\title{
El Buen Vivir y la crítica del universalismo abstracto*
}

\section{The Good Living and the criticism of abstract universalism}

O Bom Viver e a crítica do universalismo abstrato

Fecha de entrega: 7 de noviembre de 2015

Fecha de evaluación: 5 de mayo de 2016

Fecha de aprobación: 20 de junio de 2016

Edwin Cruz Rodríguez $z^{* *}$

\section{Resumen}

Este artículo reconstruye la crítica que desde el proyecto del Vivir Bien-Buen Vivir, en adelante VBBV, se puede plantear al universalismo abstracto encarnado en el discurso del desarrollo. El argumento central es que el VBBV se constituye como una alternativa a la crisis ambiental y civilizatoria contemporánea que, frente al universalismo abstracto del discurso desarrollista, reivindica un diálogo intercultural para construir relaciones de complementariedad y convivencia entre seres humanos y entre estos y la naturaleza. En primer lugar, se examina el desarrollo como un ejemplo de universal abstracto. En las tres partes siguientes

* El presente texto está vinculado con las investigaciones que el autor realiza sobre historia conceptual y teoria política en conjunto con el grupo de investigación en Teoría Política Contemporánea "Teopoco" de la Universidad Nacional de Colombia (Categoria A1 en Colciencias). DOI: http://dx.doi.org/10.15332/ s0120-8462.2016.0115.07

* Politólogo de la Universidad Nacional de Colombia (Bogotá, Colombia), especialista en Análisis de políticas públicas de la misma universidad. Magister en Análisis de Problemas Políticos, Económicos e Internacionales Contemporáneos de la Universidad Externado de Colombia (Bogotá, Colombia). Estudiante del doctorado en Estudios Políticos y Relaciones Internacionales de la Universidad Nacional de Colombia (Bogotá, Colombia). Correo electrónico: ecruzr@unal.edu.co 
se estudian las críticas que el VBBV plantea a la concepción lineal de la historia, a la concepción antropocéntrica e instrumental de la naturaleza y al carácter colonial del discurso del desarrollo.

Palabras clave: Vivir Bien-Buen Vivir, desarrollo, universalismo abstracto, colonialismo, antropocentrismo, interculturalidad.

\section{Abstract}

This article reconstructs the criticism from the project may be directed to VBBV abstract universalism embodied in the development discourse. The central argument is that the VBBV was established as an alternative to contemporary environmental and civilizational crisis, against abstract universalism of the development discourse, claimed intercultural dialogue to build relationships of complementarity and coexistence between humans and between humans and nature beings. First, the development is examined as an example of abstract universal. In the following three parts VBBV criticism raises the linear conception of history, the anthropocentric and instrumental conception of the nature and character of the colonial discourse of development are studied.

Keywords: Vivir Bien-Buen Vivir, development, abstract universalism, colonialism, anthropocentrism, interculturality.

\section{Resumo}

Este artigo reconstrói a crítica que desde o projeto do Viver Bem-Bom Viver, a partir de agora VBBV, pode-se fazer ao universalismo abstrato encarnado no discurso do desenvolvimento. $\mathrm{O}$ argumento central é que o VBBV constitui-se como uma alternativa a crise ambiental e civilizatória contemporânea que, frente ao universalismo abstrato do discurso desenvolvimentista, reivindica um dialogo intercultural para construir relações de complementaridade e convivência entre seres humanos e entre estes e a natureza. Em primeiro lugar, se examina o desenvolvimento como um exemplo de universal abstrato. Nas três seguintes partes se estudam as críticas que o VBBV apresenta à concepção linear da história, a concepção antropocêntrica e instrumental da natureza e ao caráter colonial do discurso do desenvolvimento. 
Palavras-chave: Viver Bem-Bem Viver, desenvolvimento, universalismo abstrato, colonialismo, antropocentrismo, interculturalidade.

\section{Introducción}

El universalismo abstracto no puede entenderse al margen de la historia y de las relaciones entre actores concretos. Como han sugerido Laclau (1995) y Grosfoguel (2007), tal universalismo es el resultado de unas relaciones de poder en las cuales una particularidad logra tornarse hegemónica para representar la totalidad. Tal vez en ningún otro campo se expresan más sus consecuencias negativas como cuando se trata del discurso del desarrollo, que se erigió como el modo de vida dominante desde la alocución de Harry Trumann, el 20 de enero de 1949, donde hizo invariablemente énfasis en el hecho de que todas las sociedades deberían transitar por las mismas etapas para llegar a ser "desarrolladas" (Escobar, 2007, pp. 19-20). El desarrollo, sustentado en el constante crecimiento económico, en una visión antropocéntrica e instrumental de la naturaleza y en el ilimitado consumo, es insostenible en un planeta amenazado por la crisis ambiental (Lovelock, 2011) en el que se extraen más materias primas de la naturaleza y se produce más contaminación que en cualquier otro momento (Martínez, 2011, p. 8).

La biósfera ha tocado varios límites objetivos que trastocan su funcionamiento estable, como la pérdida de biodiversidad, el cambio climático y la modificación del ciclo del nitrógeno, entre otros (Dietz, 2013, p. 473). El calentamiento global debido a las crecientes emisiones de dióxido de carbono y la huella ecológica que ha dejado el desarrollo, principalmente sustentado en el consumo de energía proveniente de la explotación de minerales fósiles, han alterado radicalmente los ciclos naturales de la biósfera, llegando a amenazar en relativamente poco tiempo las posibilidades de la vida en el planeta (Sempere, 2009). En este contexto, no es posible ni deseable que los otrora denominados países "en vías de desarrollo" aspiren a los niveles de vida, productividad y consumo de los países desarrollados, pues ello haría inviable la supervivencia de la biósfera (Acosta, 2012, p. 43), se necesitarían por lo menos seis planetas como la Tierra para llevar a cabo esa aventura (Puente, 2011, p. 358). Por consiguiente, es necesario transformar el modo de vida hegemónico.

El VBBV se presenta como un modo de vida distinto y como una opción para la supervivencia. Aunque no existe una traducción precisa de los términos con que es 
designado en aymara (suma qamaña), quechua y kichwa (suma kawsay), e incluso se pueden presentar diferencias en medio de la disputa por dotarlo de significado, el VBBV persigue la convivencia y la complementariedad entre seres humanos, y entre estos y la naturaleza, Pacha Mama o Madre Tierra y, en consecuencia, se aparta radicalmente de los supuestos en que está fundado el discurso del desarrollo.

Este artículo reconstruye la crítica que desde el proyecto del VBBV se puede plantear al universalismo abstracto encarnado en el discurso del desarrollo. El argumento central es que el VBBV se constituye como una alternativa a la crisis ambiental y civilizatoria contemporánea que, frente al universalismo abstracto del discurso desarrollista, reivindica un diálogo intercultural para construir relaciones de complementariedad y convivencia entre seres humanos y entre estos y la naturaleza. En primer lugar, se examina el desarrollo como un ejemplo de universal abstracto. En las tres partes siguientes se estudian las críticas que el VBBV plantea a la concepción lineal de la historia, a la concepción antropocéntrica e instrumental de la naturaleza y al carácter colonial del discurso del desarrollo.

\section{El desarrollo como universal abstracto}

El desarrollo es una forma particular de concebir la vida, una idea de vida buena que se presenta y se impone históricamente como si fuese universal, necesaria y deseable para todo el mundo. En otros términos, es un producto propio del devenir de la cultura europea occidental que se impone a otras culturas, a partir de prácticas coloniales (Quijano, 2007, pp. 93-94). El paradigma del desarrollo, incluso en sus más avanzadas formulaciones, está fundado en una perspectiva dual de la relación entre el ser humano y la naturaleza, en la distinción entre naturaleza y cultura, y sobre todo, en el antropocentrismo cartesiano que ve a la naturaleza como una despensa propiedad del ser humano y al servicio de sus necesidades y deseos (Zaffaroni, 2011, p. 37; Acosta, 2011, p. 321).

Incluso los modelos más heterodoxos del desarrollo, como el "desarrollo a escala humana", asumen un carácter antropocéntrico, si bien partía de una perspectiva progresista que abandonaba la cuantificación de objetos como criterio de medida del desarrollo, para centrarse en el incremento de la calidad de vida de las personas, que a su vez estaba determinado por las posibilidades que tuvieran para satisfacer sus necesidades. Según Max-Neff, Elizalde y Hopenhayn (1986), "el desarrollo se 
refiere a las personas y no a los objetos. Este es el postulado básico del desarrollo a escala humana" (p. 25).

El antropocentrismo, como se sabe, se erige como perspectiva dominante durante la modernidad, a partir del siglo XV. El proceso de cambio cultural en Europa afianzó esa mentalidad que ubicó al ser humano como algo externo a la naturaleza: la humanidad y el cultivo del espíritu, la cultura, se definieron en contraposición a la naturaleza (Acosta, 2012, p. 29). Las filosofías de F. Bacon y R. Descartes abandonaron la perspectiva organicista predominante en la edad media, donde la naturaleza era una suerte de ser viviente, siendo los seres humanos parte importante de ella (Gudynas, 2010, pp. 268-269). La industrialización y la consolidación del capitalismo profundizaron esta visión, lo cual llevó a ver a la naturaleza como una fuente inagotable de recursos de todo tipo que estaban al servicio, para extraerlos y manipularlos, del soberano ser humano. Tal perspectiva se articuló bien con el carácter colonial del discurso desarrollista para hacer de las "periferias" del sistema mundo capitalista los proveedores principales de naturaleza, de bienes primarios (Acosta, 2011, pp. 323324): el desarrollo de unos pocos significaba el subdesarrollo de la mayoría. Incluso actualmente el modelo de acumulación basado en la extracción de materias primas es visto como evidencia de la persistencia del colonialismo desarrollista (Gudynas, 2013, p. 190). En todo caso, la perspectiva antropocéntrica asume que el proceso de civilización, modernización y progreso, van aparejados al dominio de la naturaleza.

El término "desarrollo", en forma similar a las concepciones de VBBV, tiene una extraordinaria polisemia (Tortosa, 2011, p. 118). Sin embargo, todas las formas de desarrollo están sustentadas en el mito del crecimiento económico infinito, y por eso las discusiones se centran, más bien, en si es el mercado o es el Estado el que debe ser su promotor (Gudynas y Acosta, 2011a, p. 72; Sen, 1998). Como bien recuerda Gudynas (2011a, p. 111), el término "desarrollo" fue tomado directamente del campo de la biología evolutiva decimonónica, donde designaba procesos de crecimiento de distintas especies así como su trasegar por el ciclo vital. Trasplantado al campo social, el desarrollo denotó, ya en el siglo XX, la idea de un progreso lineal necesario y deseable hacia situaciones cada vez mejores.

Como es bien sabido, las alternativas para lograr el desarrollo se bifurcaron en distintas escuelas de pensamiento y programas políticos. En América Latina, por ejemplo, durante el siglo XX surgieron los enfoques estructuralista, la teoría de la dependencia y, más adelante, el neoestructuralismo (Madoery, 2012). A nivel global se introdujo 
el desarrollo sostenible, el desarrollo a escala humana, el desarrollo humano y el ecodesarrollo, entre otros (Elizalde, 2009; Unceta, 2009). Sin embargo, y aunque algunos de esos enfoques trataran de apartarse de la sinonimia entre desarrollo y crecimiento económico, en todos los casos se presuponía un buen desempeño económico medido en términos del Producto Interno Bruto (PIB), creado después de la crisis de 1929 justamente para tener un patrón de comparación del desarrollo o, en ciertos casos, del Producto Nacional Bruto (PNB) (Gabbert, 2013, p. 431).

Quizás el enfoque que más se esforzó por evitar la reducción del desarrollo al crecimiento económico fue el de "desarrollo humano", concebido durante los años noventa por el nobel de Economía Amartya Sen. Para tal efecto, este economista cuestionó la idea de ponderar el desarrollo en términos del crecimiento económico, o de otros indicadores de utilidad económica. Por el contrario, argumentó la necesidad de comprenderlo como el creciente ensanchamiento de las oportunidades de las personas para desarrollar sus capacidades. En consecuencia, se establecieron como criterios de medida aspectos como el acceso a la educación y la salud, e incluso la equidad de género, entre otros. En síntesis, para Sen (2000, p. 16), el crecimiento económico es solo un medio para conseguir la libertad y esta se constituye en el fin del desarrollo, entendido como la eliminación de diversas formas de "falta de libertad" y la correspondiente ampliación de las oportunidades.

No obstante, si bien el desarrollo humano de Sen rompió con la sinonimia entre crecimiento y desarrollo e introdujo la discusión sobre el desarrollo de las capacidades (Oriol, 2006), no se apartó de otros pilares del discurso del desarrollo, como la concepción lineal y evolutiva de la historia, el antropocentrismo o la visión instrumental de la naturaleza, entre otros. Ninguno de estos enfoques se planteó como una alternativa a la concepción de vida buena basada en el crecimiento, que enfatiza en aspectos económicos, el mito del progreso lineal y de consumo sin límite (Gudynas, 2011b, p. 2).

\section{Crítica de la concepción lineal de la historia}

Las reformas constitucionales en Bolivia (2009) y Ecuador (2008) introdujeron una perspectiva vanguardista en lo que con anterioridad se denominaba el "modelo de desarrollo", pues reconocieron y se esforzaron por ser coherentes con los postulados del Vivir Bien-Suma Qamaña y del Buen Vivir-Sumak Kawsay. Ambos conceptos fueron reconstruidos con base en las cosmovisiones de diversos pueblos y naciones o 
nacionalidades indígenas, y articulados a los proyectos políticos de los movimientos indígenas durante las últimas dos décadas. Constituyen proyectos en construcción, es decir, están sujetos a una disputa entre distintos actores por dotarlos de significado (Bonilla, 2012, p. 58). Sin embargo, parece haber un consenso cuando se trata de comparar esas cosmovisiones con el discurso de desarrollo, pues se presentan no como una forma de "desarrollo alternativo", sino como una "alternativa al desarrollo" (Acosta, 2012, p. 68; Acosta, Martínez y Sacher, 2013, p. 309).

El VBBV no se restringe a las cosmologías andinas, también está presente en las formas de pensamiento amazónicas y de otros pueblos, así que no puede hablarse de un VBBV homogéneo sino diverso como es el mundo indígena (Gudynas, 2011b, pp. 13-14). Según el intelectual aymara Simón Yampara (2012, p. 65), el Vivir Bien es una traducción aproximada del vocablo aymara Suma Qamaña, pero no expresa todo lo que este último designa. En Guaraní existe la expresión ñandereko, que también se ha traducido como una forma de buena vida, como "nuestro proceder", y que implica también relaciones de reciprocidad entre las personas y entre ellas y la Madre Tierra (Albó, 2011, p. 138). En kichwa se acepta que la traducción de Sumak Kawsay es Buen Vivir (Gudynas y Acosta, 2011a, p. 71).

Por su parte, el intelectual aymara David Choquehuanca (2010) concibe el Suma Qamaña como el "camino del equilibrio, camino que nos permita la armonía entre las personas, pero fundamentalmente la armonía entre el hombre y la naturaleza” (p. 10). Una idea central en esta concepción, profundamente arraigada en la cosmovisión y la forma de vida aymara, es la de convivencia y complementariedad. Para encontrar el camino del equilibrio, las relaciones entre los seres humanos, y entre estos y la naturaleza, deben ser de complementariedad, lo que implica que la relación sea mutuamente beneficiosa y basada en el respeto. Una relación de complementariedad es distinta a las relaciones utilitarias, donde lo determinante es el fin que se persigue con la relación, y a las relaciones de subordinación, donde una de las partes de la relación domina a la otra y extrae beneficios de ello. El mismo Choquehuanca (2010) sostiene: "todos nos necesitamos a todos. Fundamentada en el complementarnos, en el bien común, el apoyo mutuo organizado, la comunidad y la vida comunal desarrollan sus capacidades sin destruir al hombre y la naturaleza" (p. 8).

Choquehuanca distingue el Vivir Bien, traducción aproximada del Suma Qamaña aymara, del "vivir mejor" propio de las concepciones de progreso y de desarrollo que predominan en el mundo occidental: 
Mentir, robar, atentar contra la naturaleza posiblemente nos permita vivir mejor, pero eso no es Vivir Bien. Al contrario, Vivir Bien significa complementarnos y no competir, compartir y no aprovecharnos del vecino, vivir en armonía entre las personas y con la naturaleza. El Vivir Bien no es lo mismo que el vivir mejor, el vivir mejor que el otro. Porque para el vivir mejor, frente al prójimo, se hace necesario explotar, se produce una profunda competencia, se concentra la riqueza en pocas manos. Vivir mejor es egoísmo, desinterés por los demás, individualismo. El Vivir Bien está reñido con el lujo, la opulencia y el derroche, está reñido con el consumismo (Choquehuanca, 2010, p. 8).

Esto quiere decir que el Vivir Bien no se reduce al progreso o al desarrollo y, por lo tanto, no plantea como horizonte de sentido deseable el crecimiento económico o el consumo sin límite que con frecuencia se asimilan al paradigma del desarrollo. De hecho, y de acuerdo con Macas (2010, p. 15), lo que busca el Buen Vivir es ir más allá de las concepciones que ven el crecimiento económico como base necesaria de una sociedad desarrollada y del bienestar o la vida buena. En consecuencia, el rechazo del vivir mejor significa dos cosas:

Que no se aspira a vivir mejor que antes en el presente o a vivir mejor en el futuro, sino a vivir bien en el presente, pues no existe una concepción lineal y progresiva de la historia. Además, no se aspira a vivir mejor que los demás, pues ello se traduce en competencia, egoísmo, individualismo, utilitarismo y explotación del otro (Puente, 2011, p. 362).

El VBBV no significa una mejor forma de producción, crecimiento económico o consumo, ni siquiera mejorando los mecanismos de distribución, sino una alternativa al paradigma del desarrollo cuya apuesta básica es construir la "armonía entre sí y con la naturaleza", una "oportunidad" para construir colectivamente una nueva forma de vida que responda a la crisis civilizatoria y ambiental contemporánea (Acosta, 2012, p. 15). Pretende combatir la pobreza y la desigualdad, pero su concepción de la pobreza, y de lo que es necesario hacer para salir de ella, no se reduce a la carencia de bienes materiales, sino involucra la convivencia y complementariedad entre seres humanos, y entre estos y la naturaleza, e incluso la dimensión espiritual arraigada en distintas culturas; tampoco implica una noción lineal del tipo desarrollo/subdesarrollo, definida en función de criterios de escasez y la primacía de los bienes materiales. 
Por el contrario, estos quedan subordinados "a criterios ecológicos, a la dignidad humana y a la justicia social" (Escobar, 2012, p. 46). Por lo tanto, se cuestiona la idea de bienestar sustentada en la posesión de bienes materiales y el nivel de ingreso económico (Gudynas, 2011b, p. 2).

Según Albó (2011, p. 135), el vivir mejor es rechazado también porque el suma aymara, y el sumak kichwa y quechua, ya expresan "el mayor grado posible". Además, allende las distintas posiciones, existen unos consensos mínimos, como el cuestionamiento al paradigma del desarrollo que incluso en sus enfoques más moderados supone un crecimiento económico ilimitado, el cuestionamiento del progreso como un avance lineal sobre la historia y como la subordinación de la naturaleza a las necesidades y deseos de los seres humanos (antropocentrismo), e incluso la crítica al modelo de modernidad dominante. Así, el VBBV apuesta por una forma de convivencia y complementariedad, entre los seres humanos y entre estos y la naturaleza en el presente, que no ponga en riesgo la viabilidad de la biósfera.

\section{Crítica de la concepción antropocéntrica e instrumental de la naturaleza}

En contraste con el antropocentrismo del discurso desarrollista, el VBBV apuesta por superar el dualismo entre ser humano y naturaleza, por recomponer la relación de convivencia y complementariedad. Ello implica transitar de la visión antropocéntrica a una visión "socio-biocéntrica", que privilegie no la supervivencia y el bienestar de una especie determinada -como el ser humano-, sino de la vida en su conjunto (Acosta, 2012, p. 88). Así mismo, supone abandonar la valoración de todo lo existente en función de la utilidad para los seres humanos, e incluso insertar en el concepto de bienestar y de buena vida la cuestión de la felicidad, los afectos y la espiritualidad (Gudynas, 2011b, p. 3; Gudynas, 2011c, p. 244). Esta perspectiva puede fundarse en lo que Gudynas (2009, p. 88), denomina "ontologías relacionales" que anidan en las cosmovisiones indígenas y que se caracterizan porque superan el dualismo sociedad/ naturaleza, humano/no humano, e incluso animado/no animado o vivo/inerte, pues en ellas las relaciones priman sobre los elementos en sí mismos. En el mismo sentido, Estermann (1998, pp. 126-131), explica la lógica de la complementariedad de la filosofía andina como una forma de pensar que rompe con el principio de identidad propio de la racionalidad occidental. Así, algo puede ser al mismo tiempo su contrario: 
Los complementos en sentido andino no son posiciones abstractas y logomórficas, sino experiencias parciales de la realidad. Y tampoco son antagónicas en un sentido de irreconciliación racional; se requieren mutuamente, no como motor dinámico para elevarse a otro nivel, sino para complementarse en el mismo nivel (Estermann, 1998, p. 130).

Más aún, de acuerdo con Oviedo (2012, p. 53), en la tradición andina no existe la idea de cosas, objetos o elementos inanimados, se considera que todo tiene vida. Al respecto, la dirigente indígena ecuatoriana Nina Pacari (2009) explica:

Según la cosmovisión indígena, todos los seres de la naturaleza están investidos de energía que es el SAMAI y, en consecuencia, son seres que tienen vida: una piedra, un rio (agua), la montaña, el sol, las plantas, en fin, todos los seres tienen vida y ellos también disfrutan de una familia, de alegrías y tristezas al igual que el ser humano [...] en el mundo de los pueblos indígenas La Tierra no es sino allpa-mama que, según la traducción literal, significa madre-tierra. ¿Por qué esto de allpa-mama? Primero, hay una identidad de género: es mujer. Segundo, es lo más grande y sagrado, es la generadora de vida y producción; sin ella, caemos en la nada, simplemente somos la nada o no somos nadie, como dicen nuestros abuelos (pp. 33-34).

En el mismo sentido, en la cosmovisión aymara, las personas solo se conciben como individuos en la medida en que establecen relaciones con los otros seres en el marco de una comunidad. Por consiguiente, la convivencia y la complementariedad por la que apuesta el VBBV comprenden el entorno, los animales, plantas y la Pacha Mama: Por eso, de acuerdo con Albó (2011), “cuando se brinda entre amigos, por ejemplo, nunca se olvida compartir el traguito también con la Madre Tierra y con los achachilas o cerros-antepasados protectores de toda la comunidad" (p. 136).

Este tipo de pensamiento parece estar muy acendrado entre las comunidades andinas. Como sostiene el intelectual indígena boliviano David Choquehuanca (2010):

Vivir Bien es recuperar la vivencia de nuestros pueblos, recuperar la cultura de la vida y, recuperar nuestra vida en completa armonía y respeto mutuo con la madre naturaleza, con la Pacha Mama, donde todo es VIDA, donde todos somos uywas, criados de la naturaleza y del cosmos, donde todos somos parte de la 
naturaleza y no hay nada separado, donde el viento, las estrellas, las plantas, la piedra, el rocío, los cerros, las aves, el puma, son nuestros hermanos, donde la tierra es la vida misma y el hogar de todos los seres vivos (p. 10).

En el mismo sentido pueden interpretarse las palabras del intelectual aymara Pablo Mamani (2011):

Hay que aclarar que en el pensamiento aymara no hay muerte, como se entiende en el occidente donde el cuerpo desaparece en el infierno o en el cielo. Aquí la muerte es otro momento de vida más porque se revive en las montañas o en las profundidades de los lagos o rios. En realidad, los muertos se convierten en abuelos-abuelas, achachilas-abuichas. Los achachilas-abuichas son las montañas elevadas, o las montañas debajo del agua como ch'ua achachila-abuicha. Los muertos están cohabitando con los vivos, y tienen la posibilidad de proteger a sus hijos-hijas, a su ayllu-marka (unidades territoriales de organización social en los Andes), o a su gente, jaki, de peligros que, a la vez, pueden enviar castigos en forma de rayo o granizada cuando nos olvidamos de ellos y ellas (p. 69).

Esto se traduce prácticamente en una perspectiva distinta para relacionarse con la naturaleza que, más allá de la perspectiva instrumental, donde aparece subordinada a los deseos y necesidades de los seres humanos, adopta un valor en sí misma, en forma independiente de los intereses y juicios subjetivos. Por ejemplo, el reconocimiento constitucional de los derechos de la naturaleza en Ecuador se traduce en que "las plantas, animales, ecosistemas o paisajes tienen valores que son propios e independientes de los fines, percepciones o valoraciones humanas" (Gudynas, 2011c, p. 242).

Pero, además, la reformulación de la relación entre los seres humanos y la naturaleza no puede entenderse al margen del diálogo entre culturas, pues se parte de que las distintas culturas pueden establecer diversas relaciones con su entorno ecológico, y estas no se reducen a la relación instrumental que prima en la cultura occidental. Por ejemplo, como afirma el intelectual aymara Simón Yampara (2012):

Hay muchos que desde el antropocentrismo fijan al mundo de la gente como el más importante, con poder de dominio de la naturaleza por su racionalidad e inteligencia. Eso cultiva la cultura occidental y para eso hacen ciencia y tecnología. En cambio en los Andes, la gente tiene que saber vivir y convivir 
con los diversos mundos: el mundo de las deidades, el mundo de la tierra, el mundo vegetal, el mundo animal, son tan importantes al igual que el mundo de la gente. No la más ni menos importante, sino que es un miembro más dentro de la convivencia de los diversos mundos. Aquí la cultura convivencial de la vida en los Andes (p. 78).

\section{Una apuesta intercultural}

El VBBV tiene un carácter profundamente intercultural, en la medida en que si bien es una actualización de las cosmologías indígenas andinas, en esa reconstrucción participan perspectivas provenientes de distintos grupos culturales (Acosta, 2012, p. 28). En contraste, el paradigma del desarrollo es monocultural e, incluso, colonial.

Si bien esta perspectiva recupera las cosmovisiones de las comunidades indígenas en que se fundan las relaciones entre seres humanos y entre estos y la naturaleza, no pretende un retorno a un pasado mitificado, tampoco supone que todas las culturas indígenas han convivido de forma respetuosa con el medio ambiente, pues históricamente hay casos de profundas modificaciones al mismo y en el diverso mundo indígena hay distintas posiciones frente al problema, unas más respetuosas, otras más proclives a la manipulación (Gudynas, 2010, pp. 282-283). Además, el VBBV pretende construir una forma alternativa de vida que no niega o rechaza las ventajas tecnológicas del mundo moderno, que son en sí mismas producto del aporte de distintas culturas (Acosta, 2012, p. 80). Ello contrasta cuando se examina el fundamento colonial del discurso del desarrollo.

"Ser desarrolladas" implica que las sociedades deben abandonar patrones culturales propios, excluirlos si se quiere, para abrazar el patrón de vida occidental dominante, la democracia liberal en lo político, la economía de "libre" mercado en lo económico y la ética de la eficiencia, la productividad y el consumo ilimitado basada en la racionalidad instrumental. Se asume de esa forma que las expresiones de las culturas "subdesarrolladas", o situadas en la "periferia del mundo", son inferiores o no tienen nada que decir frente al bienestar de la humanidad.

Esta es una de las características nodales del colonialismo: impedir que las culturas distintas, los “otros", construyan y reivindiquen una imagen de sí mismos, una identidad, y se vean obligados a abrazar una identidad ajena o extraña (Zapata, 1997). El 
desarrollo desconoce y excluye al "otro", no solo lo domina sino que prácticamente suprime la diversidad inherente al conjunto de otredades y las uniformiza de acuerdo al patrón de vida dominante. En fin, es una forma de vida que, como se ha visto, no solo excluye otras formas de ser y de pensar arraigadas en las distintas culturas, sino que es inviable dada la crisis ambiental por la que atraviesa el mundo. En claro contraste, las cosmologías indígenas en que se funda el VBBV no sostienen una visión lineal de la historia (Escobar, 2012, p. 46) y no incluyen sino pretenden incluir en un diálogo intercultural.

Existen, principalmente, dos razones para afirmar el carácter intercultural y descolonizador del VBBV. En primer lugar, se trata de un saber de la "periferia" del mundo, producido en el seno de culturas subalternas, que cuestiona de raíz y combate aquello que ha dado en llamarse colonialismo intelectual (Tortosa, 2012, p. 1). Así, el VBBV cuestiona la más antigua idea de progreso que, para algunos autores, nació en 1492 con el origen del colonialismo (Acosta, 2012, p. 49). De acuerdo con Gudynas (2009, p. 52), de esa forma rompe con la pretensión de validez universal y excluyente del saber eurocéntrico para reivindicar saberes locales que propugnan por una relación distinta, no utilitaria, entre los seres humanos y la naturaleza.

El VBBV se constituye en el marco de lo que Boaventura de Souza Santos (2010) denomina "ecología de saberes", que apuesta en términos generales por la complementariedad entre distintas formas de conocimiento:

El fundamento de la ecología de saberes es que no hay ignorancia o conocimiento en general; toda la ignorancia es ignorante de un cierto conocimiento, y todo el conocimiento es el triunfo de una ignorancia en particular... La utopía del interconocimiento es aprender otros conocimientos sin olvidar el propio (p. 44).

Esta idea también se sustenta en el hecho de que, de acuerdo con Escobar (2010, p. 268), los conocimientos "modérnicos" presentan numerosas limitaciones para proyectar alternativas frente a la crisis ambiental y civilizatoria contemporánea o, si se quiere, tal crisis, que articula distintos problemas modernos, no tiene necesariamente soluciones modernas. La ciencia no necesariamente debe ser el único conocimiento con legitimidad para pronunciarse sobre esos problemas (Lovelock, 2011). Es ello lo que hace necesario reivindicar lo que Escobar denomina los conocimientos 
"pachamámicos", que pueden brindar alternativas, como el VBBV, pero siempre en ese proceso de ecología de saberes.

La segunda razón para afirmar el carácter descolonizador del VBBV es que, como antes se afirmaba, es una construcción polisémica e intercultural, que se alimenta de los aportes de los diversos significados insertos en las cosmovisones de los pueblos y naciones indígenas, pero también de los saberes acumulados en la cultura occidental. Así, a diferencia del colonialismo inserto en el discurso del desarrollo, no establece una jerarquía entre los saberes y tradiciones de las distintas culturas, y no excluye sino al contrario intenta poner en diálogo e incluir. El VBBV solo puede entenderse desde una perspectiva intercultural, dado que los líderes indígenas que lo reivindican retoman elementos de la cultura occidental y también los intelectuales occidentales articulan a él elementos de las culturas indígenas (Caudillo, 2012, p. 345).

Por consiguiente, a diferencia del desarrollo, el VBBV no se presenta como un universal a priori cuyo destino fuera imponerse sobre las concepciones de vida buena acendradas en otras culturas, sino más bien como un universal a posteriori, pues pretende encontrar equivalencias entre el VBBV y las concepciones de vida buena acendradas en otras culturas a partir del diálogo. Por ejemplo, Walsh (2009, pp. 216-223), establece interesantes equivalencias entre el "bien estar colectivo" de las comunidades afroecuatorianas y el VBBV, que empiezan por la visión holística de la realidad y su rechazo al antropocentrismo y la concepción instrumental de la naturaleza propias del concepto de desarrollo occidental. En forma similar, Albó (2011) pregunta:

¿No hay también mucho del suma qamaña, por ejemplo, en el saludo hebraico y bíblico shalom, que significa paz en sus diversas acepciones tanto individuales como colectivas e internacionales, y también bien estar y retorno al equilibrio, a la justicia y la igualdad integral? ¿No encontramos también principios semejantes en muchas otras religiones orientales? (pp. 140-141).

En fin, como afirma un intelectual indígena:

Todos los pueblos en su cosmovisión contemplan aspectos comunes sobre el Vivir Bien que podemos sintetizar en: vivir bien es la vida en plenitud. Saber vivir en armonía y equilibrio; en armonía con los ciclos de la Madre Tierra, del 
cosmos, de la vida y de la historia, y en equilibrio con toda forma de existencia en permanente respeto (Huanacuni, 2010, p. 32).

De esa forma, el VBBV enfatiza la necesidad del diálogo intercultural como elemento necesario para construir alternativas de vida viables en el mundo contemporáneo. Se trata de "una propuesta como opción de vida para todos, no es una propuesta indígena para los pueblos indígenas sino para toda la sociedad” (Macas, 2010, p. 16). Si bien se alimenta de las cosmovisiones indígenas ancestrales, no se plantea como un proyecto solo para los indios ni como un retorno al pasado, sino como un proyecto para la humanidad y una alternativa a la crisis de la civilización capitalista. La dirigente indígena ecuatoriana, Blanca Chancoso (2010), a este respecto enfatiza la necesidad de traducción entre las distintas culturas:

Podría ser llamado una utopía porque lo que reclama y propone es la lucha constante por la igualdad: la propuesta del Sumak Kawsay es incluyente, tiene en cuenta a mujeres, niños, ancianos, indios, afros, mestizos, es para toda la sociedad. Más bien pueden traducirla desde su idioma y desde su cultura. Esta palabra no es solo para indígenas porque está en nuestro idioma, miremos más bien la interpretación que cada uno le puede dar en el marco del cambio para alcanzar el Buen Vivir (p. 6).

En fin, el Buen Vivir rescata saberes y filosofías de las culturas indígenas, pero también incorpora saberes occidentales, tales como las conceptualizaciones del feminismo y las posturas éticas que defienden otro tipo de relación entre seres humanos y naturaleza como la "ecología profunda" (Gudynas y Acosta, 2011a, p. 74; Gudynas y Acosta, 2011b, p. 80).

\section{Corolario}

En estas líneas se ha tratado de reconstruir la crítica que el VBBV hace al universalismo abstracto propio del discurso desarrollista. Ese universalismo radica en que bajo la concepción de desarrollo se impuso un modo de vida hegemónico, el occidental, como si fuese necesario y deseable para todas las demás culturas y sociedades. Ello ha tenido consecuencias perversas en términos de la amenaza en que está sumida la biósfera por efecto de la crisis ambiental a la que condujo el desarrollo, basado en el crecimiento, la 
producción y el consumo ilimitados. Pero también ha tenido consecuencias negativas desde el punto de vista de la dominación cultural, pues todo universalismo abstracto debe convertirse, para erigirse como tal, en una forma de colonialismo.

En contraste con el carácter colonial, antropocéntrico y eficientista del discurso desarrollista, el VBBV apuesta por un modo de vida intercultural, holístico y posdesarrollista. Más que a un concepto preciso, la crítica del VBBV y su erección como una alternativa al desarrollo, se dirige al discurso del desarrollo o su "régimen de representación", que articula prácticas y significaciones, pensamiento y acción, como la forma de vida dominante en occidente desde mediados del siglo XX, más que a una teoría o enfoque específico (Escobar, 2007, pp. 29-30).

El VBBV está presente en el campo que busca opciones para, como dice Sempere (2010, p. 8), "modificar radicalmente el metabolismo socionatural", esto es, hacer que la satisfacción de las necesidades humanas, que siempre requerirá recursos naturales de distinta índole, no amenace la preservación de la biósfera y, por ende, de la especie humana. Ello plantea la necesidad de un cambio cultural, que implica modificar las necesidades producto del devenir histórico de la humanidad, pero también un cambio de naturaleza socioeconómica, que implicará obligatoriamente consumir menos recursos naturales y menos energía, producir menos desechos y emisiones, para mantener la huella ecológica de la humanidad en su conjunto, así como construir un sistema económico cuyas leyes se acoplen a las leyes del sistema ecológico o la biósfera.

Pese a su polisemia, el VBBV tiene una perspectiva normativa más amplia que el desarrollo o posdesarrollista, que implica construir relaciones de complementariedad entre seres humanos y entre estos y la naturaleza. Propugna por generar un modo de vida alternativo al desarrollo, que vaya más allá de la idea de crecimiento económico sin límites y por tanto insostenible, esto es, "superar la idea de progreso entendida como permanente acumulación de bienes materiales y tecnológicos" (Acosta, 2012, p. 33). Ello significa superar la visión lineal de la historia y el antropocentrismo en que se sustenta el desarrollo, abandonando la visión instrumental de la naturaleza y reconociendo sus limitaciones objetivas; así como superar las desigualdades e inequidades, realizar la descolonización y la despatriarcalización, acabar con el racismo y hacer frente a la desigualdad social y la pobreza (Acosta, 2012, p. 22). También cuestiona la idea de bienestar reducido a un problema económico que puede resolverse por el 
mercado, y se inclina, en su lugar, por imaginar una calidad de vida no reducida al consumo ilimitado (Gudynas, 2011b, p. 2).

En fin, el VBBV reivindica un universalismo concreto, concebido no como un punto de partida, como una norma a la que el otro o el diferente debe acoplarse o adaptarse, sino como una construcción producto del diálogo y la traducción interculturales sobre aquello que las diversas culturas consideran una vida en armonía entre los seres humanos y entre estos y la naturaleza.

\section{Referencias}

Acosta, A., Martínez, E., y Sacher, W. (2013). Salir del extractivismo: una condición para el Sumak Kawsay. Propuestas sobre petróleo, minería y energía en Ecuador. En Lang, M., López, C., y Santillana, A. (Comps.). Alternativas al capitalismo del siglo XXI. Quito: Abya Yala, Fundación Rosa Luxemburgo.

Acosta, A. (2011). Los derechos de la naturaleza. Una lectura sobre el derecho a la existencia. En Acosta, A., y Martínez, E. (Comps.). La naturaleza con derechos. De la filosofía a la política. Quito: Abya Yala.

Acosta, A. (2012). Buen Vivir Sumak Kawsay. Una oportunidad para imaginar nuevos mundos. Quito: Abya Yala.

Albó, X. (2011). Suma qamaña = convivir bien. ¿Cómo medirlo? En Farah, I., y Vasapollo, L. (Coords.). Vivir Bien: ¿paradigma no capitalista? La Paz: CIDES-UMSA.

Bonilla, A. (2012). Del extractivismo al Sumak Kawsay. En Velardi, N., y Zeisser, M. (Comps.). Anales seminario internacional desarrollo territorial y extractivismo. Luchas y alternativas en la Región Andina. Cuzco: Centro Bartolomé de las Casas.

Brand, U., y Wissen, M. (2013). Crisis socioecológica y modo de vida imperial. Crisis y continuación de las relaciones sociedad-naturaleza en el capitalismo. En Lang, M., López, C., y Santillana, A. (Comps.). Alternativas al capitalismo del siglo XXI. Quito: Abya Yala, Fundación Rosa Luxemburgo.

Casas, M. (2011). Una mirada económica hacia el Vivir Bien. En Farah, I., y Vasapollo, L. (Coords.). Vivir Bien: ¿paradigma no capitalista? La Paz: CIDES-UMSA. 
Caudillo, F., y Gloria, A. (2012). El Buen Vivir: un diálogo intercultural. En Ra-Ximhai, 8(2).

Cortéz, D. (2009). Genealogía del Buen Vivir en la Nueva Constitución Ecuatoriana. En Ponencia presentada en el VIII International Congress for Intercultural Philosophy. Good life as humanized life. Concepts of good life in different cultures and their meanings for politics and societies today. Seoul: Ewha Womans University.

Chancoso, B. (2010, marzo). El Sumak Kawsay desde la visión de la mujer. En América Latina en Movimiento ALAI. Alternativas Civilizatorias: los viejos nuevos sentidos de humanidad, (453). Quito, Ecuador: II Epoca.

Choquehuanca, D. (2010). Hacia la reconstrucción del Vivir Bien. En América Latina en Movimiento, 452.

Dietz, K. (2013). Reacciones emancipatorias frente a la crisis. En Lang, M., López, C., y Santillana, A. (Comps.). Alternativas al capitalismo del siglo XXI. Quito: Abya Yala, Fundación Rosa Luxemburgo.

Elizalde, A. (2009). ¿Qué desarrollo puede llamarse sostenible en el siglo XXI? La cuestión de los límites y las necesidades humanas. En Revista de Educación, número extraordinario.

Escobar, A. (2007). La invención del tercer mundo. Construcción y deconstrucción del desarrollo. Caracas: Fundación Editorial El Perro y la Rana.

Escobar, A. (2010). ¿Pachamámicos versus modernos? En Tabula Rasa, 15.

Escobar, A. (2012). Más allá del desarrollo: postdesarrollo y transiciones hacia el pluriverso. En Revista de Antropología Social, 21.

Estermann, J. (1998). Filosofía andina: estudio intercultural de la sabiduría autóctona. Quito: Abya Yala.

Gabbert, K. (2013). Hay que dejar de crecer. Acerca del postcrecimiento. En Lang, M., López, C., y Santillana, A. (Comps.). Alternativas al capitalismo del siglo XXI. Quito: Abya Yala, Fundación Rosa Luxemburgo.

Grosfoguel, R. (2007). Descolonizando los universalismos occidentales: el pluriversalismo transmoderno decolonial desde Aimé Césaire hasta los zapatistas. En Quijano, A., (2007). Colonialidad del poder y clasificación social. En Castro, S. y 
Grosfoguel, R. (Eds.). El giro decolonial: reflexiones para una diversidad epistémica más allá del capitalismo global. Pontificia Universidad Javeriana. Bogotá: Siglo del Hombre Editores.

Gudynas, E. (2009). Ciudadanía ambiental y meta-ciudadanías ecológicas: revisión y alternativas en América Latina. En Desenvolvimento e meio ambiente, 19. Universidad Federal Paraná.

Gudynas, E. (2009). La dimensión ecológica del Buen Vivir. Entre el fantasma de la modernidad y el desafío biocéntrico. En Revista Obets, 4.

Gudynas, E. (2010). Imágenes, ideas y conceptos sobre la naturaleza en América Latina. En Montenegro, L. (Ed.). Cultura y naturaleza. Bogotá: Jardín Botánico J. C. Mutis.

Gudynas, E. (2010). La senda biocéntrica: valores intrínsecos, derechos de la naturaleza y justicia ecológica. En Tabula Rasa, 13.

Gudynas, E. (2011a). Ambiente, sustentabilidad y desarrollo. En Reyes, J., y Castro, E. (Eds.). Contornos educativos de la sustentabilidad. México: Universidad de Guadalajara.

Gudynas, E. (2011b). Buen Vivir: germinando alternativas al desarrollo. En América Latina en Movimiento, 462.

Gudynas, E. (2011c). Tensiones, contradicciones y oportunidades de la dimensión ambiental del Buen Vivir. En Farah, I., y Vasapollo, L. (Coords.) Vivir Bien: ¿paradigma no capitalista? La Paz: CIDES-UMSA-Plural.

Gudynas, E. (2013). Postextractivismo y alternativas al desarrollo desde la sociedad civil. En Lang, M., López, C., y Santillana, A. (Comps.). Alternativas al capitalismo del siglo XXI. Quito: Abya Yala, Fundación Rosa Luxemburgo.

Gudynas, E., y Acosta, A. (2011a). El Buen Vivir más allá del desarrollo. En Quéhacer, 181.

Gudynas, E., y Acosta, A. (2011b). La renovación de la crítica al desarrollo y el Buen Vivir como alternativa. En Utopía y praxis latinoamericana, 16(53).

Gudynas, E., y Acosta, A. (2011c). El Buen Vivir o la disolución de la idea de progreso. En Rojas, M. (Comp.). Medición del progreso y del bienestar, propuestas desde América Latina. México: Foro Consultivo Científico y Tecnológico. 
Huanacuni, F. (2010). Definición del vivir bien. En Buen Vivir/Vivir Bien, filosofía, políticas, estrategias y experiencias regionales andinas. Lima: Coordinadora Andina de Organizaciones Indígnas, CAOI.

Huanacuni, F. (2010). Paradigma occidental y paradigma originario. En América Latina en movimiento, 452.

Laclau, E. (1996). Why do empty signifiers matter to politics? En Emancipations. London: Verso.

Lovelock, J. (2011). La tierra se agota. Bogotá: Planeta.

Macas, L. (2010). Sumak Kawsay: la vida en plenitud. En América Latina en movimiento, 452 .

Madoery, O. (2012). El desarrollo como categoría política. En Crítica y Emancipación, 7(4).

Mamani, P. (2011). Qamir qamaña: dureza de "estar estando" y dulzura de "ser siendo". En Farah, I., y Vasapollo, L. (Coords.). Vivir Bien: ¿paradigma no capitalista? La Paz: CIDES-UMSA.

Martínez, E. (2011). Prólogo. En Acosta, A., y Martínez, E. (Comps.). La naturaleza con derechos. De la filosofía a la política. Quito: Abya Yala.

Max-Neff, M., Elizalde, A., y Hopenhayn, M. (1986). Desarrollo a escala humana, una opción para el futuro. Santiago de Chile: Development Dialogue.

Medina, J. (2011). Acerca del Suma Qamaña. En Farah, I., y Vasapollo, L. (Coords.). Vivir Bien: ¿paradigma no capitalista? La Paz: CIDES-UMSA.

Morales, E. (2011). Prólogo. En Farah, I., y Vasapollo, L. (Coords.). Vivir Bien: ¿paradigma no capitalista? La Paz: CIDES-UMSA.

Oriol, J. (2006). Teoría y práctica del desarrollo. Cambios en las variables de la ecuación del desarrollo en los últimos 50 años. En Reforma y Democracia, 36.

Oviedo, F., y Atawallpa, M. (2012). El posmoderno Buen Vivir y el ancestral Sumak Kawsay. En Guillén, A., y Phelan, M. Construyendo el Buen vivir. Cuenca: Pydlos Ediciones. 
Pacari, N. (2009). Naturaleza y territorio desde la mirada de los pueblos indígenas. En Acosta, A., y Esperanza, M. (Comp.). Derechos de la naturaleza. El futuro es ahora. Quito: Abya Yala.

Prada, R. (2011). El Buen Vivir como modelo de Estado y modelo económico. En Lang, M., y Mokrani, D. (Eds.). Más allá del desarrollo. Quito: Abya-Yala-Fundación Rosa Luxemburgo.

Puente, R. (2011). Vivir Bien y descolonización. En Farah, I., y Vasapollo, L. (Coords.). Vivir Bien: ¿paradigma no capitalista? La Paz: CIDES-UMSA.

Quijano, A. (2007). Colonialidad del poder y clasificación social. En Castro, S., y Grosfoguel, R. (Eds.). El giro decolonial: reflexiones para una diversidad epistémica más allá del capitalismo global. Pontificia Universidad Javeriana. Bogotá: Siglo del Hombre Editores.

Quijano, A. (2011). Bien vivir: entre el desarrollo y la des/colonialidad del poder. En Debate, 84. Ecuador.

Rostow, W. (1961). Las etapas del crecimiento económico. México: Fondo de Cultura Económica.

Santos, B. (2010a). Refundación del Estado en América Latina. Lima: ILDIS.

Santos, B. (2010b). Hablamos de socialismo del Buen Vivir. En América Latina en movimiento, 452.

Sempere, J. (2009). Mejor con menos. Necesidades, explosión consumista y crisis ecológica. Barcelona: Crítica.

Sempere, J. (2010). Autocontención: mejor con menos. En del Viso Nuria (Ed.). Enfoques sobre bienestar y Buen Vivir. Madrid: Centro de Investigación para la Paz.

Sen, A. (1998). Las teorías del desarrollo a comienzos del siglo XXI. En Cuadernos de Economía, 29. Bogotá.

Sen, A. (2000). Desarrollo y libertad. Barcelona: Planeta.

Simbaña, F. (2011). El Sumak Kawsay como proyecto político. En Lang, M., y Mokrani, D. (Eds.). Más allá del desarrollo. Quito: Abya-Yala-Fundación Rosa Luxemburgo. 
Tortosa, J. (2011). Cambios de época en la lógica del desarrollo. En Debate, 84. Ecuador.

Tortosa, J. (2012). Sumak Kawsay, Buen Vivir, ¿alternativa al desarrollo? Recuperado de: http://www.universitatdelapau.org/files/23-41201 document/sumak_kawsay_sant_cugat.pdf

Unceta, K. (2009). Desarrollo, subdesarrollo, maldesarrollo y postdesarrollo. Una mirada transdisciplinar sobre el debate y sus implicaciones. En Carta latinoamericana, 7.

Vega, E. (2011). Descolonizar y despatriarcalizar para vivir bien. En Lang, M., y Mokrani, D. (Eds.). Más allá del desarrollo. Quito: Abya-Yala-Fundación Rosa Luxemburgo.

Walsh, C. (2009). Interculturalidad, Estado, sociedad. Quito: Abya Yala.

Yampara, S. (2012). Suma Qamaña, lo que se maneja como Buen Vivir. En Velardi, N., y Zeisser, M. (Comps.). Anales seminario internacional desarrollo territorial y extractivismo. Luchas y alternativas en la Región Andina. Cuzco: Centro Bartolomé de las Casas.

Zaffaroni, E. (2011). La Pachamama y el humano. En Acosta, A., y Martínez, E. (Comps.) La naturaleza con derechos. De la filosofía a la política. Quito: Abya Yala. 